\title{
REMAJA DAN PANDANGANNYA TERHADAP CYBERBULLYING PADA MEDIA FACEBOOK
}

\author{
Yunus Winoto ${ }^{1}$, Adi Rahmat Sopian ${ }^{2}$ \\ ${ }^{1,2}$ Program Studi Ilmu Komunikasi Universitas Padjadjaran \\ Email : yunuswinoto@gmail.com
}

\begin{abstract}
The study aims to determine the views of teenagers on cyberbullying activities on Facebook media. The study was conducted on high school students. In the context of communication there are two aspects that are examined in relation to cyberbullying activities, namely verbal and non verbal aspects with three indicators namely interactivity, connectivity and access. The method used in this study is quantitative with a desricptive survey approach. The theory used as a basis in examining this problem is the theory of radical change which measures how much the views of adolescents see cyberbullying activities. The population in this study were students and for the sampling technique using simple random sampling technique. Data analysis was performed using descriptive analysis techniques. Based on the results of the study, it was found that teenagers were seen from aspects of interactivity, connectivity and access which were generally quite good. Whereas seen from the form of communication in cyberbullying activities, teenagers are of the view that cyberbullying that is verbally treated will look more violent, cruel and more sadistic. Whereas if cyberbullying is conveyed by using non-verbal language, especially if it is presented using funny pictures and symbols even though it is still an act that is less commendable in the eyes of the teenagers, it will not be so painful for the person bullied. This research is expected to contribute to teenagers to wisely use social media, especially Facebook media.
\end{abstract}

Keywords: cyberbullying, adolescents, verbal and non-verbal language, facebook.

\section{PENDAHULUAN}

Seiring dengan perkembangan zaman, teknologi informasi dan komunikasi yang saat ini mulai berkembang dengan pesat sehingga perkembangan teknologi ini dapat menandai bahwa teknologi di Indonesia sudah menjadi bentuk kehidupan, salah satu kemajuan teknologi yang sangat berkembang di masyarakat adalah Internet karena Internet saat ini menjadi salah satu sarana informasi dan komunikasi. Bukan hal tabu lagi bagi masyarakat dengan kehadiran internet karena internet sangat membantu manusia dalam menjalankan aktivitasnya, dengan kehadiran internet itu sendiri berbagai informasi pun dapat diperoleh dengan waktu dan tempat yang tidak dibatasi sehingga internet dapat diakses di mana saja.

Berdasarkan hasil survei Asosiasi Penyelenggara Jasa Internet Indonesia (2014) dalam jurnal Yuniarin Putri Haryanto yang dilakukan pada bulan 1 November 2014 sampai 28 Februari 2015 menunjukan bahwa jumlah pengguna internet sebesar 71,2 juta pada tahun 2013 menjadi sebesar 88,1 juta pada tahun 2014-2015 ini, dari jumlah penggguna internet tersebut $84.7 \%$ adalah pengguna aktif media sosial. Hasil serupa juga ditujukkan oleh hasil 
riset dari We Are Social pada tahun 2016 menunjukkan bahwa terdapat sebanyak 88,1 juta pengguna internet aktif dan 79 juta nya adalah pengguna media sosial aktif, dimana $85 \%$ mengakses media sosial menggunakan perangkat mobile atau handphone, dari hasil riset tersebut menunujukkan bahwa hampir semua pengguna internet memiliki dan menggunakan media sosial.

Media sosial adalah sebuah media online yang memudahkan penggunanya untuk berpartisipasi, berbagi, dan menciptakan isi yang meliputi blog, jejaring sosial, wiki, forum, dan dunia virtual. Saat ini media sosial yang berkembang di masyarakat cukup banyak, antara lain, Instagram, Facebook, Twitter, Google+, Tumblr, You Tube, Blog, Path, dan lain-lain. Menurut Liputan6.com yang di muat pada tanggal 21 april 2017 dalam artikel yang di tulis oleh Jeko Jeko I.R Indonesia menduduki peringkat ke-4 di dunia dengan pengguna Facebook paling aktif. Hal ini diungkap dari laporan riset We Are Social dan Hootsuite yang dirilis di Lin kedIn, Jumat (21/4/2017). Facebook diklaim kian mendominasi jagat media sosial di dunia. Sampai saat ini, raksasa media sosial milik Mark Zuckerberg itu sudah mengantongi 1.968 miliar pengguna aktif. Sebanyak 89 persen di antaranya mengakses via smartphone dan 61 persen mengakses Facebook setiap harinya. Setelah dipecah berdasarkan gender, 44 persen pengguna adalah wanita dan 56 persen merupakan pria
Facebook telah menjadi bagian dari gaya hidup yang mana gaya hidup diciptakan dari aktivitas rutin setiap orang (Reyns, 2010). Withall dalam (Sheldon, 2008) yang dikutip oleh Siti Nurjanah pada tahun 2014, mengungkapkan bahwa murid-murid menjadikan Facebook sebagai Social Bible atau menjadi pedoman dalam kehidupan sosial yang penting untuk mencari informasi dan berhubungan dengan teman sekelas, orang yang ditaksir, teman yang sudah lama mereka tidak ditemui, hingga orang yang baru mereka kenal. Konten-konten dalam facebook terdiri dari artikel, berita, video, dan lain sebagainya. Konten facebook memiliki sifat positif dan negatif. Konten yang bersifat negatif itu dapat memicu terjadinya tindakan bullying atau yang lebih dikenal dengan istilah cyberbullying. Konten negatif tersebut dapat berupa komenkomen negatif terhadap suatu artikel atau tulisan yang di posting dalam suatu akun facebook (Hate speech), gambar-gambar atau foto editan yang bersifat mengejek atau menjatuhkan seseorang, berita-berita yang belum tentu benar kebenarannya dan lain sebagainya. Sedangkan konten yang bersifat positif dalam facebook yaitu bertambahnya pertemanan, mempromosikan produk/jasa, dan lain sebagainya.

Bully juga memiliki arti yaitu tindakan menyakiti orang lain baik itu secara fisik maupun psikologis, yang seringkali dilakukan oleh individu atau kelompok yang lebih kuat 
atau berkuasa. Korban bully akan merasa sangat tertekan dan banyak korban bully berakhir dengan bunuh diri. Menurut Ken Rigby (2008), Bully adalah sebuah hasrat untuk menyakiti, hasrat ini diperlihatkan dalam sebuah aksi dan menyebabkan seseorang menderita. Aksi ini dilakukan oleh seseorang atau kelompok yang lebih kuat, tidak bertanggung jawab, biasanya berulang dan dilakukan dengan perasaan senang.

Cyberbullying merupakan bentuk perilaku mengintimidasi atau mengejek melalui sarana teknologi atau dunia maya (cyber) yang dilakukan secara berulang yang menyebabkan ketidaknyamanan pada orang lain (korban cyberbullying). Menurut Patchin dan Hunduja (2012) mengemukakan bahwa korban bully di media sosial berkemungkinan besar menjadi korban bully juga di sekolah. Cyberbullying kini banyak dilakukan oleh para remaja terutama dalam media sosial seperti Facebook, Twitter, Instagram, Path dan masih banyak lagi. Dalam sebuah penelitian yang dilakukan oleh www.knowthenet.org.uk, mendapatkan hasil bahwa media sosial Facebook menempati posisi tertinggi sebagai media atau tempat untuk melalukan tindakan cyberbullying yaitu sebesar $87 \%$. Menurut hasil penelitian ini juga dikatakan bahwa sebanyak $49 \%$ remaja diketahui menjadi korban bully pada dunia nyata sedangkan $65 \%$ dari mereka adalah korban dari cyberbullying (Akbar, 2015, 4). Hal ini dikarenakan internet atau media sosial bisa dilihat dan diakses oleh semua orang di seluruh dunia, sehingga menimbulkan tekanan yang lebih besar pula dibandingkan dengan bully biasa yang hanya diketahui di lingkungan sekitar saja, biasanya korban cyberbullying dilakukan oleh remaja.

Remaja pada saat ini menganggap bahwa dunia maya merupakan dunia bagi mereka untuk bisa berekspresi, mengutarakan pendapat, menuangkan perasaan dalam bentuk kekaguman, kesukaan ataupun ketidaksukaan dan bahkan kemarahan terhadap suatu hal tertentu. Bentuk ekspresi tersebut dapat berupa tulisan, gambar, foto ataupun bentuk audio visual. Remaja merasa bebas untuk menuliskan atau berkomentar apa saja pada media sosial tanpa memikirkan akibat yang mungkin akan timbul dari hasil tulisan atau komentar mereka. Hal ini dapat terjadi karena kurangnya pengawasan dari orang tua atau bahkan bentuk pembiaran dari orang tua dan atau bahkan ketidaktahuan orang tua terkait dengan kegiatan anak-anak remaja di media sosial, dan juga kurangnya self-control dari remaja itu sendiri. Cyberbullying ini dapat terjadi karena kurangnya pemahaman remaja dalam menggunakan internet yang baik dan benar. Dampak lain dari ketidakpahaman ini bisa berhubungan langsung pada sikap dan tindakan mereka. Cyberbullying juga terjadi dikarenakan pengalaman-pengalaman yang dilihat dan didengar dari tontonan di televisi yang bernada hinaan dan hujatan. 
Tindakan cyberbullying pada media sosial tidak mengarah kepada perempuan atau laki-laki saja, dengan kata lain cyberbullying tidak mengenal jenis kelamin (gender). Juvonen (2008) dan Patchin \& Hinduja (2012) menyatakan bahwa cyberbullying tidak mengenal jenis kelamin. Dalam pemaparan Lindfors et al (2012), beberapa penelitian menunjukan keseimbangan dalam hal siapa yang menjadi korban cyberbullying baik lakilaki maupun perempuan.

Menurut Ayunintgyas (2013), perilaku cyberbullying di Indonesia sebenarnya adalah masalah baru seiring dengan perkembangan teknologi informasi. Belum banyak penelitian yang memfokuskan diri untuk mengangkat masalah ini sehingga kasus cyberbullying ini juga tidak dapat terungkap kepermukaan seluruhnya, padahal dampak kaus ini cukup berbahaya. Dampak cyberbullying hampir sama dengan bullying tradisonal bahkan dampaknya bisa lebih dari tradisional bullying.

Menurut kasus cyberbullying pada Facebook, komunikator adalah pelaku cyberbullying dan komunikan adalah korban cyberbullying. Pesan dalam kasus cyberbullying adalah interaksi teks antara dua belah pihak. Teks dalam sosial media Facebook dapat dikirimkan melalui pesan personal, komentar maupun status. Pesan inilah yang menjadi dominan dalam perilaku cyberbullying yang dilakukan remaja di Facebook. Pesan menjadi medium utama dalam mengirimkan serangan verbal pelaku terhadap korban.

Komunikator mempunyai cara sendiri dalam mengdekode pesan dan tiap komunikator berbeda dalam mengemas pesan. Begitu juga dengan komunikan mempunyai cara sendiri dalam bereaksi terhadap pesan. Tiap komunikator juga berbeda dalam menggunakan kata-kata dalam pesannya sehingga membentuk kategori cyberbullying yang berbeda satu sama lain.

Melihat fenomena ini, dapat terlihat bahwa kegiatan cyberbullying dapat terjadi akibat ketidaktahuan seseorang dalam menggunggah suatu konten yang dapat menimbulkan tindakan cyberbullying. Oleh karena itu, sebaiknya pengguna media facebook lebih bisa memilih konten mana yang seharusnya diunggah, sehingga tidak terjadi tindakan cyberbullying. Berkaitan dengan hal ini peneliti terkait untuk mengkaji pandangan remaja terhadap kegiatan cyberbullying pada media facebook.

\section{METODOLOGI PENELITIAN}

Penelitian ini menggunakan pendekatan kuantitatif dengan jenis survey. Adapun mengenai penelitian survey yaitu suatu metode dalam penelitian yang mengambil sampel dari suatu populasi dan menggunakan angket sebagai alat pengumpulan data yang pokok". (Singarimbun 1989, 3). Populasi dalam penelitian ini adalah para siswa Sekolah Menengah Atas (SMA) Rancaekek dengan teknik pengambilan sampel menggunakan 
simpel random sampling. Untuk teknik pengambilan sampelnya dilakukan melalui angket, wawancara, observasi serta melalui studi kepustakaan.

\section{HASIL DAN PEMBAHASAN}

Sebagaimana yang telah dikemukakan di awal tulisan ini, penelitian ini bermaksud mengkaji tentang pandangan para remaja terhadap kegiatan cyberbullying pada media sosial facebook. Teori yang dipergunakan dalam penelitian ini mengguna-kan teori perubahan radikal. Adapun mengenai teori perubahan radikal ini menurut Eliza T. Dresang (1981) di latar belakangi dari aspek informasi kekinian yang dengan nyata menguasai alam pemikiran dan aktivitas masyarakat saat ini sehingga informasi itu lebih bersifat global dan untuk mendapatkannya cukup berbasis elektronik, seperti internet.

Masih tentang teori Perubahan Radikal (radical change theory) yang di kembangkan Eliza T. Dresang memiliki tiga konsep yang dapat mempengaruhi perilaku anak muda atau remaja, yakni :

1) Interaktivitas, yakni aktivitas interaktif anak muda baik bertatap muka secara langsung maupun tidak langsung (menggunakan media). Disini interaktivitas dipandang sebagai suatu 'event' yang melibatkan 'pemakai, media dan informasi'. Sedangkan William Rice dan Rogers mendefinisikan interaktivitas adalah sebagai derajat dimana partisipan dalam proses interaksinya tetap memiliki kontrol, dan dapat bertukar peran dalam aspek mutual discource (Jancowski dan Hansen, 1996). Dalam teori perubahan radikal (radical change theory), konsep interaktivitas itu dinamis, dan sejalan dengan pandangan masyarakat dan budaya.

2) Konektivitas, lebih dikaitkan dengan konsep ruang dan waktu dalam terjadinya suatu peristiwa, atau bersifat kausalitatif (sebab-akibat). Konektivitas itu didasari oleh suatu kesadaran dan pengembangan sosial yang menghubungkan suatu kelompok dengan kelompok lain, sehingga memiliki jangkauan yang semakin luas

3) Akses, yakni kemudahan yang dimiliki seseorang ataupun society (masyarakat) untuk mendapatkan informasi publik dengan cepat.

Dari ketiga indikator di atas yakni interaktivitas, konektivitas dan akses terhadap media sosial facebook terungkap bahwa :

\section{Aspek Interaktivitas}

Dilihat dari aspek interaktivitas remaja yang menggunakan media facebook berkaitan dengan cyberbullying termasuk dalam kategori 
cukup. Hal ini terlhat pada tabel sebagai berikut

Table 1 : Aspek Interaktivitas

\begin{tabular}{|c|c|c|c|}
\hline Sub Variabel & Kategori & $\mathbf{f}$ & \% \\
\hline \multirow{3}{*}{ Interaktivitas } & Buruk & 19 & 22.6 \\
\cline { 2 - 4 } & Cukup & 47 & 56.0 \\
\cline { 2 - 4 } & Baik & 18 & 21.4 \\
\hline \multicolumn{2}{|c|}{ Jumlah } & $\mathbf{8 4}$ & $\mathbf{1 0 0}$ \\
\hline
\end{tabular}

Berdasarkan hasil pengolahan data

terhadap 84 orang responden yang disajikan pada tabel tersebut di atas menunjukkan bahwa para remaja sebenarnya tidak menyukai kegiatan atau aktivitas yang bersifat cyberbullying yang dilakukan melalui media facebook. Hal ini sangat beralasan karena hakekatnya setiap orang juga tidak mau diperlakukan tidak baik apalagi di bullying oleh orang lain.

Berbicara tentang pengertian bullying sebenar berasal dari asal kata bully, yakni mengacu pada pengertian adanya "ancaman" yang dilakukan seseorang terhadap orang lain yang menimbulkan gangguan psikis bagi korbannya berupa stress yang muncul dalam bentuk gangguan fisik atau psikis, atau keduanya. Menurut Ken Rigby dalam (Astuti 2008 ; 3, dalam Ariesto, 2009 ; Ela Zain, 2017) bullying adalah "sebuah hasrat untuk menyakiti. Aksi ini dilakukan secara langsung oleh seseorang atau kelompok yang lebih kuat, tidak bertanggung jawab, biasanya berulang, dan dilakukan dengan senang.
Lebih jauh tentang pengertian bullying merujuk pada batasan yang dikemukakan Komisi Nasional Perlindungan Anak adalah kekerasan fisik dan psikologis berjangka panjang yang dilakukan seseorang atau kelompok terhadap seseorang yang tidak mampu mempertahankan diri. Dapat dikatakan pula bullying adalah tindakan yang dilakukan seseorang secara sengaja membuat orang lain takut atau terancam sehingga menyebabkan korban merasa takut, terancam, atau setidaktidaknya tidak bahagia. Dalam konteks ini juga bullying dikategorikan sebagai perilaku antisosial atau misconduct behavior dengan menyalahgunakan kekuatannya kepada korban yang lemah, secara individu ataupun kelompok, dan biasanya terjadi berulang kali. Bullying dikatakan sebagai salah satu bentuk delinkuensi (kenalakan anak), karena perilaku tersebut melanggar norma masyarakat, dan dapat dikenai hukuman oleh lembaga hukum.

Kemudian jika dilihat dari bentuknya bullying dapat dikelompokkan dalam tiga kategori, yaitu :

a) Bullying fisik, meliputi tindakan: menampar, menimpuk, menginjak kaki, menjegal, meludahi, memalak, melempar dengan barang, serta menghukum dengan berlari keliling lapangan atau push up.

b) Bullying verbal, terdeteksi karena tertangkap oleh indera pendengaran, seperti memaki, menghina, menjuluki, meneriaki, memalukan di depan umum, menuduh, menyebar gossip dan menyebar fitnah. 
c) Bullying mental atau psikologis, merupakan jenis bullying paling berbahaya karena bullying bentuk ini langsung menyerang mental atau psikologis korban, tidak tertangkap mata atau pendengaran, seperti memandang sinis, meneror lewat pesan atau sms, mempermalukan, dan mencibir.

Apabila di atas dikemukakan bullying, maka pengertian cyberbullying adalah segala bentuk kekerasan yang dialami anak atau remaja dan dilakukan teman seusia mereka melalui dunia cyber atau internet. Cyberbullying adalah kejadian manakala seorang diejek, dihina, diintimidasi, atau dipermalukan orang lain melalui media internet, teknologi digital, atau telepon seluler. Misalnya pelaku dengan sengaja dan sadar memosting di FB atau mention ke twitter lawan untuk mencomooh atau mengintimidasi (Nasrullah, 2015 : 188).

\section{Aspek Konektivitas}

Setelah mengetahui akibat dari adanya cyberbullying sebagai suatu tindakan yang buruk langkah selanjutnya adalah untuk menegetahui seberapa besar pengaruh internet dalam aksi cyberbullying dilihat dari sisi verbal maupun non verbal. Adapun dari tabel di bawah ini terungkap bahwa :
Table 2 : Aspek Konektivitas

\begin{tabular}{|c|c|c|c|}
\hline $\begin{array}{c}\text { Sub } \\
\text { Variabel }\end{array}$ & Kategori & $\mathbf{f}$ & \% \\
\hline \multirow{3}{*}{ Konektivtas } & Buruk & 18 & 21.4 \\
\cline { 2 - 4 } & Cukup & 51 & 60.7 \\
\cline { 2 - 4 } & Baik & 15 & 17.9 \\
\hline \multicolumn{2}{|c|}{ Jumlah } & $\mathbf{8 4}$ & $\mathbf{1 0 0}$ \\
\hline
\end{tabular}

Tabel di atas, menjelaskan tentang pandangan respondeng mengenai kegiatan cyberbullying pada media facebook dilihat dari aspek komunikasi verbal dan non-verbal. Berdasarkan hasil penyebaran angket terhadap 84 orang responden terungkap bahwa bahwa sebagian besar responden atau sebanyak 51 (60.7\%) menunjukkan aspek pendekatan atau metode yang digunakan termasuk dalam kategori cukup baik, sebanyak 18 orang (21.4\%) berada pada kategori buruk serta sisanya yakni sebanyak 15 orang lagi atau sekitar (17.9\%) berada dalam kategori baik. Jadi berdasarkan tabel di atas, dapat dikatakan bahwa untuk Konektivitas yakni pandangan remaja terhadap kegiatan cyberbullying pada media Facebook dilihat dari sisi verbal dan non-verbal tersebut dapat dikatakan cukup baik, karena sebagain orang lebih tidak suka terhadap kegiatan cyberbullying akan tetapi untuk pilihan verbal dan non-verbal para remaja lebih cenderung lebih menyukai kegiatan cyberbullying yang berbentuk non verbal. 


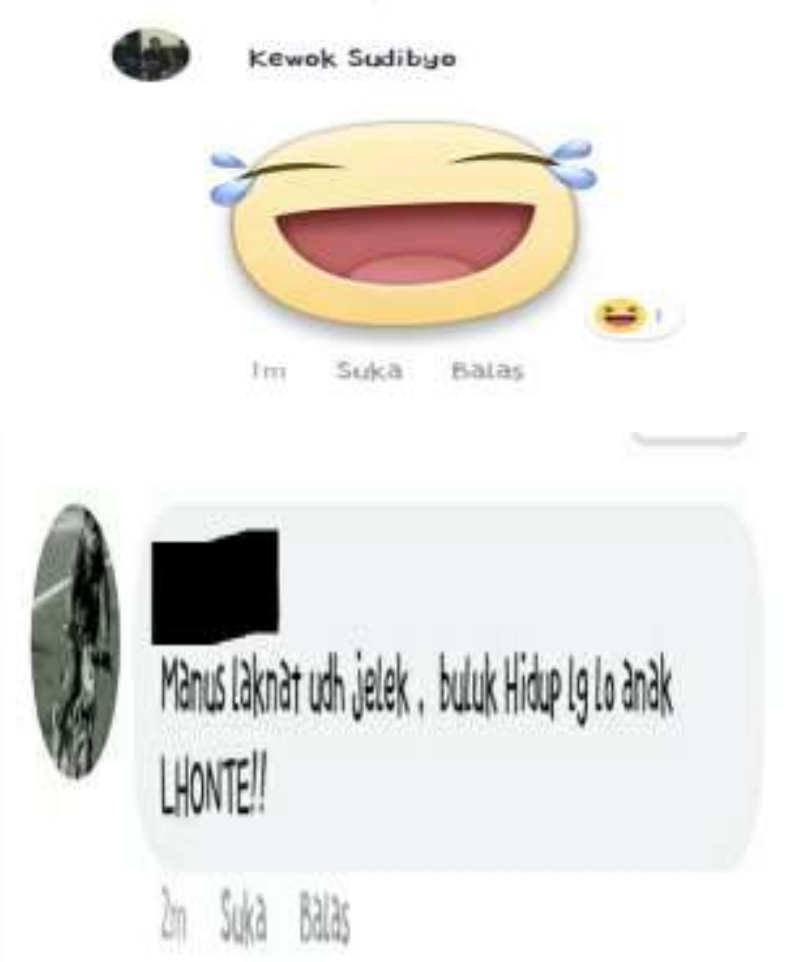

\section{Gambar 1 : Bahasa Nonverbal dalam Cyberbullying Media Facebook}

Berbicara tentang perilaku cyberbullying hakekatnya adalah suatu kegiatan komunikasi yang dilakukan oleh seseorang pada orang lain. Berkaitan dengan hal ini Onong Ucjhana Effendy (2000 : 13) mengartikan komunikasi adalah suatu proses penyampaian pikiran atau perasaan oleh seseorang kepada orang lain dengan menggunakan lambanglambang yang bermakna pagi kedua pihak, dalam situasi yang tertentu untuk merubah sikap atau tingkah laku seorang atau sejumlah orang sehingga ada efek tertentu yang di harapkan. Dalam konsep komunikasi dikenal adanya istilah komunikasi verbal dan komunikasi non verbal.

Pengertian komunikasi verbal adalah komunikasi yang didasarkan pada interaksi antarmanusia yang menggunakan kata-kata lisan atau tertulis secara sadar dan dilakukan untuk berhubungan dengan manusia lain
(Deddy Mulyana, 2002). Komunikasi verbal bisa juga bermuatan konten negatif salah satunya Cyberbullying, seperti dalam penelitian ini yaitu dapat dilakukan melalui tulisan, contohnya mengomentari orang lain, membuat kata-kata hinaan, pendapat yang merendahkan, dan pemberian nama negative terhadap orang lain.

Masih tentang perilaku cyberbullying, selain melalui komunikasi verbal kegiatan cyberbullying juga dapat dilakukan melalui komunikasi atau pesan non verbal. Adapun komunikasi nonverbal adalah komunikasi yang menggunakan isyarat bukan kata-kata (Mulyana 2010, 343). Sedangkan Larry A. Samovar dan Richard E. Porter, komunikasi nonverbal mencakup semua rangsangan (kecuali rangsangan verbal) dalam suatu setting komunikasi, yang dihasilkan oleh individu dan penggunaan lingkungan oleh individu, yang mempunyai nilai pesan potensial bagi pengirim atau penerima (Samovar and Porter 1991, 179).

\section{Kemudahan Akses Informasi}

Aspek ketiga dalam perilaku cyberbullying melalui media facebook adalah berkaitan dengan kemudahan akses informasi. Hal ini berkaitan dengan kemudahan dalam mengases informasi serta kemudahan dalam menyebarkan informasi pada orang lain. Berkaitan dengan aspek kemudahan akses informasi ini dapat dikemukakan pada tabel sebagai berikut. 
Table 3 : Kemudahan Akses

\begin{tabular}{|c|c|c|c|}
\hline Variabel & Kategori & $\mathbf{f}$ & \% \\
\hline \multirow{3}{*}{ AKSES } & Buruk & 18 & 21.4 \\
\cline { 2 - 4 } & Cukup & 49 & 58.3 \\
\cline { 2 - 4 } & Baik & 17 & 20.2 \\
\hline \multicolumn{2}{|c|}{ Jumlah } & $\mathbf{8 4}$ & $\mathbf{1 0 0}$ \\
\hline
\end{tabular}

Tabel di atas menjelaskan tentang padangan responden berkaitan perilaku cyberbullying pada media facebook kaitannya dengan kemudahan dalam mengakses informasi baik pesan yang bersifat verbal maupun pesan-pesan yang bersifat non verbal. Dari tabel tersebut terungkap bahwa sebagian besar responden berpandangan bahwa dengan adanya kemudahan dalam mengakses informasi melalui media facebook responden bisa dengan mudah menyebarluaskan konten-konten apa saja yang ingin mereka kirim termasuk konten cyberbullying verbal maupun non verbal, untuk hasil yang didapatkan dari kusioner yang dibagikan konten non-verbal lebih disukai karena konten non-verbal memuat konten hinaan yang sudah termanipulasi dengan warna, gambar, tanda dan simbol yang lebih bisa diterima dikarenakan memiliki artian dan/atau pemaknaan yang lebih terbuka.
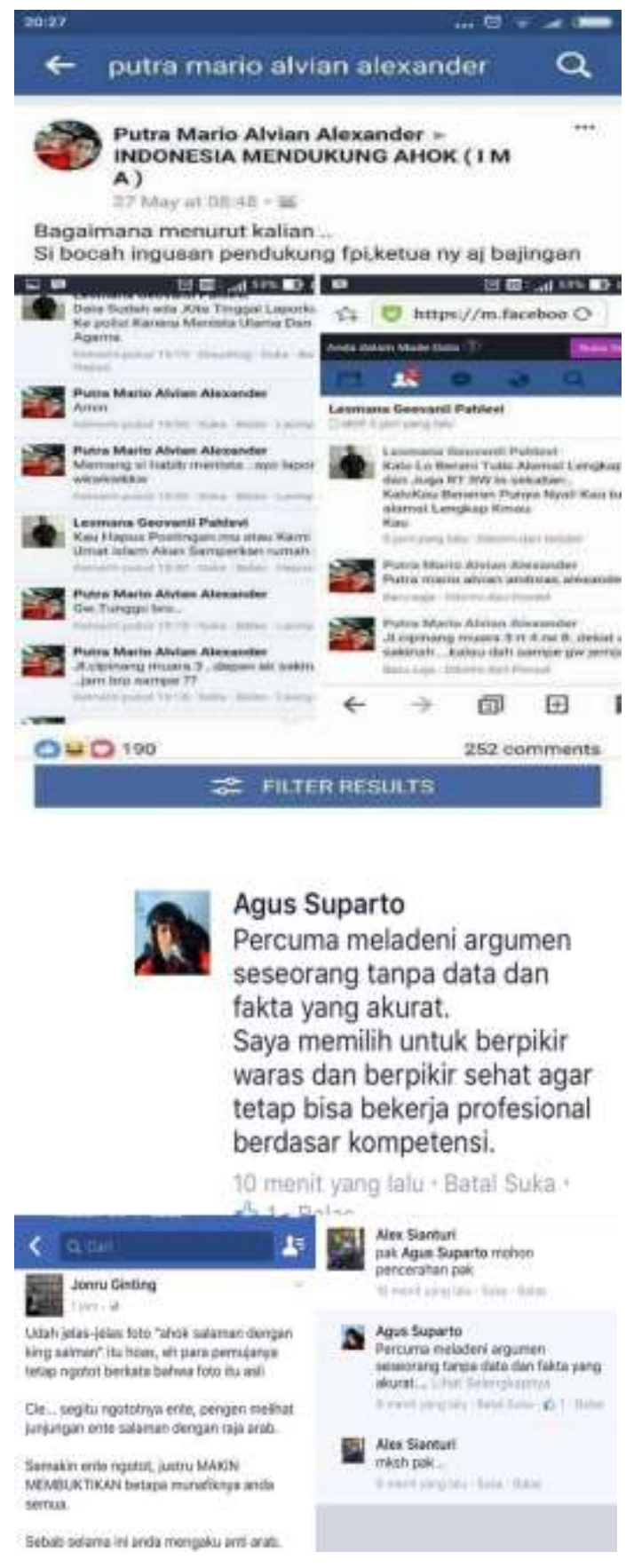

Berdasarkan uraian tersebut di atas, maka dapat dikemukakan perilaku Cyberbullying pada media facebook dalam padangan remaja dipengaruhi oleh tigas hal yakni interaktivitas diantara orang-orang yang terlibat berinteraksi dalam media facebook, konektivitas serta kemudahan akses informasi. Semakin mudah akses informasi akan semakin 
mudah seseorang dalam menerima dan juga menyebarkan pesan-pesan cyberbullying pada orang lain. Sedangkan mengenai pesan komunikasi yang disampaikan dalam cyberbullying menurut pandangan para remaja akan lebih pesan-pesan yang bersifat verbal akan lebih terasa kasar, vulgar dan terasa sangat kejam jiga dibandingkan perilaku cyberbullying yang disampaikan melalui pesan-pesan non verbal.

\section{PENUTUP}

Hadirnya media sosial seperti media facebook telah memberikan pengaruh dalam kehidupan masyarakat. Orang akan dengan mudah untuk mengakses informasi dan menyebarluaskan pada orang lain termasuk informasi yang bersifat bulyying. Berkaitan dengan hal tersebut berdasarkan hasil penelitian dapat dikemukakan kesimpulan sebagai berikut

1) Kegiatan cyberbullying dalam media facebook dipengaruhi oleh tiga hal yakni interaktivitas yakni seberapa besar proses interaksi diantara para pengguna facebook; konektivitas yakni berkaitan dengan kemampuan dan jangkuan akses diantara pengguna facebook. Hal ini juga terkait dengan beberapa kelebihan dari media facebook yang terkait dengan masalah konektivitas, serta kemudahan akses informasi. Dengan kata lain semakin mudah dalam mengakses informasi melalui media facebook maka akan semakin mudah seseorang dalam menerima dan menyebarkan informasiinformasi yang bersifat bullying.

2) Kemudian berkaitan dengan pesanpesan verbal dan non verbal kaitannya dengan perilaku cyberbullying, menurut pandangan para remaja cyberbullying pada media facebook yang disampaikan melalui pesan-pesan yang bersifat verbal akan terasa kasar, vulgar dan terasa lebih menyakitkan dibandingkan dengan pesan yang disampaikan secara non verbal, karena cyberbullying yang disampaikan dalam bentuk non verbal bisa dikemas dalam bentuk gambar, meme dan simbol-simbol lainnya sehingga tidak akan begitu terasa pada orang yang menerimanya.

\section{DAFTAR PUSTAKA}

Akbar, Muhammad Alam dan Prahasriwi Utari.(2015). Cyberbullying pada Media Sosial (Studi Analisis isi tentang Cyberbullying pada Remaja di Facebook). Jurnal Komunikasi Massa, ISSN. 1411-268x Vol. 1. Surakarta: Universitas Sebelas Maret Surakarta. http://www.jurnalkommas.com/docs/JU RNAL\%20-\%20FIX.pdf./

Arifin, Hasnul. (2009). Nongkrong Asyik di Internet Dengan Facebook. Jakarta: Buku Kita.

Darmawan, Deni. 2014. Metode Penelitian Kuantitatif. Bandung: Remaja Rosda Karya.

Hall, Stuart. (2002). Encoding and Decoding in 
Television Discourse. Birmingham, England: Centre for Cultural Studies, University of Birmingham

Hertz MF, David-Ferdon C. Electronic Media and Youth Violence: A CDC Issue Brief for Educators and Caregivers. Atlanta (GA): Centers for Disease Control; 2008.http://www.cdc.gov/ncipc/dvp/YV

P/electronic_aggression

Liliweri, Alo. 1994. Komunikasi Verbal Dan Nonverbal. Bandung: Citra Aditya Bakti. Maya, N. (2015). Fenomena cyberbullying di kalangan pelajar. Jurnal Ilmu Sosial dan Ilmu Politik, 4(3), 443-450. Diambil dari http://digilib.unila.ac.id/

25131/8/SKRIPSI TANPA BAB PEMBAHASAN.pdf

Mulyana, Deddy. 2002. Ilmu Komunikasi Suatu Pengantar. Bandung Rosda karya.

Mulyana, Deddy. Ilmu Komunikasi suatu pengantar. Bandung: Remaja Rosda karya, 2010.

Nasrullah, R. (2013). Cybermedia. Yogyakarta : IDEA Press.

Nasrullah,R. (2015). Media Sosial. Remaja Rosdakarya, Bandung

Nurjanah, S. (2014). Pengaruh Penggunaan Media Sosial Facebook Terhadap Perilaku Cyberbullying Pada Siswa SMAN 12 Pekanbaru, 1(2), 1-8. Diambil dari http://digilib.its.ac.id/ public/ITS-paper-24346-5208100061Paper.pdf

O’Keefe, B. J. dan Bruce L. L. (1988). Effect of Message Design Logic on The Content and Communication of Situation Presentasion. Indiana : University of Illinois

Patchin, Justin W dan Sameer Hinduja. (2006). Bullies Move Beyond the Schoolyard: A Preliminary Look at Cybebrullying. Florida Atlantic University. Youth Violence and Juvenile Justice, Vol.4 No.

h.148169.https://www.researchgate.net /profile/Sameer_Hinduja/publication/2 58201014_Bullies_Move_Beyond_the _Schoolyard_A_Preliminary_Look_at_ Cyberbullying/links/554cbf9b0cf29f83 6c99ea10.pdf/

Pearson, Judy. Human Communication. New york: Mc Graw Hill Companies, 2003.

Prijana, Wina Erwina dan Yunus Winoto. (2017). Model \& Teori Ilmu Informasi dan Perpustakaaan. Bandung : Unpad Press

Purwanto. (2011). Statistika Untuk Penelitian. Yogyakarta: Pustaka Pelajar.

Putri, Fanny Aulia. (2014). Opini Siswa terhadap Cyberbullying di Media Sosial. Medan: Universitas Sumatera Utara.

http://repository.usu.ac.id/bitstream/12 3456789/42287/4/Chapter\%20II.pdf/

Riyantoro, B. (2013). Efektivitas Iklan Melalui Jejaring Sosial Sebagai Salah Satu Strategi Pemasaran Keripik Pedas Maicih, 5, 8-9. Diambil dari www.ejournal. gunadarma.ac.id/ index.php/pesat/article/download/923/8 13

Rohman, F. (2016). Analisis Meningkatnya Kejahatan Cyberbullying Dan Hatespeech Menggunakan Berbagai Media Sosial Dan Metode Pencegahannya. Seminar Nasional Ilmu Pengetahuan dan, 387. Diambil dari http://konferensi.nusamandiri.ac.id/pro siding/index.php/sniptek/article/view/4 5

Samovar, Laar A., and Richard E. Porter.

Communication Between Culture.

Belmont: Wadsworth, 1991.

Sugiyono. 2009. Metode Penelitian

Kuantitatif, Kualitatif, dan $R \& D$. Bandung: Alfabeta.

Sugiyono. 2014. Statistika Untuk Penelitian. Bandung: ALFABETA, cv.

Zittrain, J.L. "Reflections on internet culture." Journal of Visual Culture 13, no. 3 (2014): 383-394.

Setyawati, I. (2016). Pengaruh Cyberbullying di Media Sosial ASK.FM Terhadap Gangguna Emosional Remaja. Diambil dari http://digilib.unila.ac.id/ 25131/8/SKRIPSI TANPA BAB PEMBAHASAN.pdf

Utami, Y. C. (2014). Cyberbullying Dikalangan Remaja, 12. Diambil dari 
journal.unair.ac.id/download-

fullpapers-kmnts73d7a00d3dfull.pdf

Zakiyah, Ela Zain, S. H. (2017). Faktor yang mempengaruhi remaja dalam melakukan Bullying. Penelitian Dan $P P M, \quad 4, \quad 324-330$. Diambil dari http://jurnal.unpad.ac.id/prosiding/artic le/viewFile/14352/6931. 